\section{Propuesta de un diccionario biográfico de escritores costarricenses (DIBEC)}

\author{
Alexánder Sánchez Mora*
}

\section{RESUMEN}

Los diccionarios biográficos son un tipo de producción textual que no ha gozado de particular prestigio, tanto dentro del campo lexicográfico como del literario. Esta condición marginal ha incidido en su escaso desarrollo en Costa Rica. Este artículo pretende reivindicar el papel destacado del diccionario biográfico como texto de consulta básica y, en forma paralela, dar a conocer el proyecto de elaboración del "Diccionario Biográfico de Escritores Costarricenses" (DIBEC).

\footnotetext{
Profesor de la Escuela de Filología, Lingüística y Literatura de la UCR e investigador del Instituto de Investigaciones Lingüísticas de la UCR.

Ponencia presentada en el III Coloquio Costarricense de Lexicografía, celebrado en la Facultad de Letras de la Universidad de Costa Rica, del 2 al 4 de noviembre de 2005.

Rec. 26-01-06 Acep. 19-04-06
}

\section{Palabras clave}

Diccionario biográfico, Campo léxico gráfico, Costa Rica, Biografía.

\begin{abstract}
Biographic dictionaries are a type of textual production that has not particularly enjoyed prestige within neither Lexicography nor Literature. This discrimination has influenced its lacking development in Costa Rica. The article attempts to restore the distinguished role of the biographic dictionary as a basic reference text and to make known the preparation project of the Diccionario Biográfico de Escritores Costarricenses (DIBEC, Biographic Dictionary of Costa Rican Authors).
\end{abstract}

\section{Keywords}

Biographic dictionary, Lexicography, Costa Rica, Biography

Biografia pornografia respetable, gracias a la cual el lector puede ser un mirón en la vida de una persona famosa. John R. Saul, Diccionario del que duda.

\section{Diccionarios biográficos: desventuras de un género menor}

El arte de hacer diccionarios biográficos hunde sus raíces en la antigüedad. Aunque se citan las obras de Plutarco (Vidas), Cornelio Nepote (De Viris Illustribus) y Suetonio (De Vita Caesarum) como sus antecedentes, así como ciertos textos medievales (el Lexicon 
Suidas, que además de diccionario de la lengua griega contiene datos biográficos de escritores griegos y bizantinos, y Las vidas dels Trobadors sobre poetas provenzales), el diccionario biográfico, tal y como se le conoce en la actualidad, aparece en el siglo XVI. Slocum reseña 16 diccionarios en ese siglo, 64 en el XVII (incluido el primero español, la Biblioteca Hispana Vetus (1672) y la Biblioteca Hispana Nova (1696) de Nicolás Antonio) y 346 en el XVIII (1967:xv-xvi). Durante los siglos XIX y XX, se produce una verdadera proliferación que imposibilita cualquier intento enumerativo.

A pesar de esta larga tradición, la labor de producir diccionarios biográficos no es una de las que goza de mayor prestigio académico. Visto con recelo tanto desde la lexicografía como desde el campo literario, no es un trabajo que depare a sus cultores un especial aprecio o consideración intelectual.

Ante la mirada de los estudiosos de la literatura, este empeño corre el riesgo de ser visto como una nostálgica reminiscencia de los estudios positivistas que pretendían explicar el texto en función de la vida de su autor. En una época deudora de aquella famosa proclama barthesiana de "la muerte del autor", parece arriesgado, entonces, apostar por el estudio de la poética del emisor (Pozuelo Yvancos, 1992:107). Esta clase de textos es vista como una producción ancilar, carente de fundamentos teóricos y de escasa o ninguna rigurosidad metodológica, en fin, prácticamente un pasatiempo de legos.

A esta censura se puede añadir otra que me gustaría ejemplificar con un cuento de Alí Víquez que, casualmente, lleva por título "Biografías de hombres ilustres". En dicho relato, el impresor de ese diccionario biográfico se enfrenta a la tarea de añadir 15 páginas de personajes célebres en la letra $Z$, en específico después del apellido Zudinsky. Tras constatar la dificultad de encontrar el suficiente número de personajes famosos con apellidos que por fatalidad alfabética se pudieran colocar después de Zudinsky, y presionado por la premura de finalizar la impresión, decide incluir los nombres de los primeros individuos con apellido iniciado en $Z$ que pudiera localizar. La decisión no fue fácil, pero le fueron de mucho ayuda los cinco güisquis que la acompañaron. Así que tomó la guía telefónica e insertó en las biografías de hombres ilustres hasta "a aquel primo de su cuñada de apellido Zúñiga, que nadie pensó que sirviera para nada y ya ven, ahí está, héroe anónimo rescatado del olvido al que 
la incomprensión humana destina a los más humildes" (Víquez, 2002:110).

Este relato, mediante su fina ironía, desmonta las bases generales del diccionario biográfico en el tanto desautoriza su criterio selectivo: la condición de celebridad o fama de las vidas reseñadas. Así, a los hombres ilustres, canonizados por la historia oficial y considerados como los únicos cuya biografía merece conocerse, opone la noción de héroe cotidiano: "muchos otros héroes de los que nada se sabe, nada ilustres o famosos pero héroes al fin que luchan día a día y se llenan de coraje y dan la cara pero nadie la recuerda ni se aprende nadie sus nombres" (Víquez, 2002: 109-110).

Las perspectivas para el diccionario biográfico no son más halagüeñas desde el punto de vista de la lexicografía. Hay quienes estiman que emplear el término diccionario para denominar un catálogo de biografías es un uso abusivo que desnaturaliza su contenido o, en el mejor de los casos, un préstamo (Seco, 1987:49). Para Alvar Ezquerra, por ejemplo, en sentido estricto diccionario es solo el diccionario lingüístico, es decir, aquella obra confeccionada según criterios lexicográficos y dirigida a precisar el significado de las palabras de una lengua o de un lenguaje especia- lizado (1980:104). La extensión de esta denominación a otras obras que son catálogos de noticias no lingüísticas organizadas según un criterio alfabético, en consecuencia, se justifica únicamente por el "enorme prestigio que tienen los diccionarios de la lengua (en especial el académico) dentro de nuestra cultura" (1980:104). Si bien Alvar Ezquerra reconoce la utilidad de los diccionarios no lingüísticos, los etiqueta, en sentido peyorativo, como "meros productos comerciales en mayor o menor grado". Esta es una muestra de un purismo lexicográfico que minimiza la relevancia cognoscitiva de otros modelos investigativos; resulta difícil, para citar solo un caso, considerar el Dizionario Biografico degli Italiani, un esfuerzo de décadas del Istituto della Enciclopedia Italiana, uno de cuyos directores fue Guglielmo Marconi, como una simple aventura mercantil.2

En suma, esta subvaloración ha determinado que no se le haya prestado atención teórica al diccionario biográfico: "probablemente,

2. En honor a la verdad, se debe reconocer que, en otro texto, Alvar Ezquerra (1976: 17-18) juzga con criterio más amplio la importancia de la investigación enciclopédica: "Su rigor científico suele ser comparable a la (sic) de los 'diccionarios', pero tiene en su favor no ser una obra esencialmente lingüística, por lo que cae fuera de los límites de nuestro trabajo". 
por entender que cae fuera de los límites de nuestra disciplina o por no considerar digno de interés el 'espurio' resultado fruto de una 'lamentable' confusión entre lengua y realidad" (Hernández, 1994:61).

\section{Hacia una definición del diccionario biográfico}

Cuestionada, así, tanto por críticos literarios como por lexicógrafos, ¿cómo definir la producción textual etiquetada como diccionario biográfico?

Como resulta evidente de lo expuesto en el apartado anterior, dentro de la división clásica y ampliamente compartida de diccionarios lingüísticos y no lingüísticos o enciclopedias, los biográficos se ubican en este último grupo. La enciclopedia informa sobre las cosas, sobre una materia determinada, es decir, ofrece una amplia variedad de datos sobre el mundo extralingüístico (Haensch, 1982:129; Seco, 1987:32; Alvar, 2001:42). No pretende reflejar un conjunto de signos, tarea del diccionario lingüístico, sino describir en forma pormenorizada un repertorio de cosas, esto es, la realidad. Su discurso cumple una función didáctica en cuanto ofrece una imagen del mundo, de allí la profusión de nombres propios e ilustraciones (Ahumada Lara, 1989:138).
Existe un género híbrido, el diccionario enciclopédico, que combina la definición lingüística de palabras y la definición enciclopédica para referirse a los conocimientos humanos sobre determinada materia. El diccionario biográfico no se identifica a plenitud con tal caracterización, puesto que prescinde de la definición lingüística y se concentra en exclusiva en la enciclopédica. Por ello, y en consonancia con la clasificación de diccionarios propuesta por Martínez de Sousa, se debe precisar que el diccionario biográfico, sin ser un diccionario enciclopédico, sigue un criterio enciclopédico. A mayor abundamiento, se ubica dentro de la categoría de "diccionario de cosas":

Diccionario que define conceptos, describe objetos y narra hechos o procesos mediante descripción enciclopédica. Nota. En un diccionario de cosas estricto no aparecen definidas las palabras gramaticales (preposiciones, conjunciones, pronombres, artículos, etc.), sino solo los nombres de las cosas (conceptos abstractos, personas, herramientas, animales, hechos culturales, etc.) (Martínez de Sousa, 1995:133).

El diccionario biográfico, en consecuencia, es un diccionario que tiene por objeto la descripción de 
la vida de personas consideradas de relevancia social en un momento histórico determinado.3 El criterio de selección de la macroestructura en este tipo de diccionario responde, como norma general, a dos consideraciones básicas: las oposiciones general/especial, y universal/nacional, regional, etc.

Los diccionarios de carácter general incluyen biografías de personas de cualquier categoría posible (artistas, políticos, científicos, militares, etc.), en tanto que los de carácter especial se concentran en solo una determinada (diccionario de médicos, de escritores, de mujeres, de extranjeros, etc.). Como se aprecia, el criterio de categoría no es homogéneo, por cuanto responde tanto a campos de actividad profesional como a otros criterios tales como el género o la condición de extranjería.

Los diccionarios biográficos universales comprenden la vida de personas de cualquier país del mundo sin excepción alguna y los nacionales o regionales se limitan,

3. La definición de Martínez de Sousa (1995:131): “Diccionario que describe la biografía de las personas de un campo determinado," no satisface, por cuanto es restrictiva en exceso y deja de lado aquellos diccionarios biográficos que no se limitan a un campo determinado (diccionario biográfico universal) o que siguen otros criterios (diccionario biográfico de género, de extranjería, etc.). como lo indica su denominación, a los individuos de un espacio geográfico restringido por fronteras de diverso tipo (país, región, ciudad, etc.).

La combinación de estos dos pares opositivos produce, en la práctica, cuatro tipos básicos de diccionarios biográficos:

\section{1) General-universal \\ 2) General-nacional o regional \\ 3) Especial-universal \\ 4) Especial-nacional o regional4}

Los siguientes ejemplos de diccionarios biográficos concretos ilustran este prurito clasificador:

1) General-universal: diccionario biográfico universal, $\mathrm{o}$ resumen histórico de los personajes célebres de todos los países del globo: desde los tiempos más remotos hasta la época presente (1862),

4. Nótese que para elaborar esta clasificación se ha tomado como primer elemento la oposición general/especial y como segundo la oposición universal/nacional, regional. Esta decisión es arbitraria y perfectamente puede ser invertida para producir los siguientes cuatro tipos de diccionarios biográficos: 1) universal-general; 2) universal-especial; 3) nacional o regional-general; y 4) nacional o regional-especial. 
Diccionario de biografias (2001), Dictionnaire des biographies (1958).

2) General-nacional o regional: los ejemplos más famosos son el Oxford Dictionary of National Biography, el Dizionario Biografico degli Italiani y el "Diccionario Biográfico Español" en elaboración; Diccionario biográfico-histórico dominicano (1971), Diccionario biográfico general del antiguo departamento del Cauca: colonia, independencia y república (1910), Diccionario biográfico argentino (1938).

3) Especial-universal: Dictionnaire biographique du mouvement ouvrier international (1996), Diccionario de actores, (1995), Diccionario biográfico universal de mujeres célebres o Compendio de la vida de todas las mujeres que han adquirido celebridad en las naciones antiguas y modernas, desde los tiempos más remotos hasta nuestros días (1851),

Diccionario biográfico de la música (1956).

4) Especial-nacional o regional: Diccionario biográfico de extranjeros en Chile (1900), Dictionnaire biographique $d u$ mouvement ouvrier français (43 volúmenes publicados entre 1964 y 1993), Diccionario de literatos hondureños (1997),
Diccionario de bibliotecólogos latinoamericanos y especialistas afines: una aproximación (1999).

\section{La breve historia de los diccionarios biográficos en Costa Rica}

Cualquier intento por elaborar un diccionario no puede hacer tabla rasa del pasado, es decir, no debe hacer caso omiso de los trabajos lexicográficos precedentes. Como bien señala Mederos, los diccionarios "son obras que copian, abrevian, amplían y revisan el caudal de voces y acepciones de diccionarios precedentes" (1994:97). Este mismo principio es el conocido en la teoría literaria como intertextualidad, y según el cual cualquier texto, no solo los diccionarios, dialoga con todos los textos que lo han precedido de modo tal que la escritura deviene en un proceso de reescritura de la entera tradición textual.

Este fenómeno no es menos cierto en el caso de los diccionarios biográficos, por lo que es conveniente formular un estado de la cuestión para el contexto costarricense. En este país, y esta es una observación fácilmente constatable, los diccionarios biográficos no han tenido un gran desarrollo. Durante el siglo XIX, en el marco de los procesos de invención de las naciones europeas 
y latinoamericanas, ${ }^{5}$ la producción de diccionarios biográficos nacionales conoce su mayor esplendor (Slocum, 1967:xvii). En el caso de Costa Rica, sin embargo, el proceso es tardío e inconstante. El pionero en el cultivo del género es el historiador, diplomático y escritor Ricardo Fernández Guardia, quien publica, apenas en 1941, el Diccionario biográfico de Costa Rica. Época del descubrimiento y la conquista.

Después de este texto inaugural solamente se han producido dos más de carácter general: el anteproyecto Diccionario Biográfico Costarricense (1985) de Elías Zeledón Cartín y el Diccionario biográfico costarricense (1992) de Malavassi y Gutiérrez.6 En el primer caso, se trata de un anteproyecto que no llegó a concretarse en una obra mayor. Contiene únicamente 82 biografías, 35 de ellas referidas a escritores.

El Diccionario biográfico costarricense de Malavassi y Gutiérrez es, enton-

5. Parto del concepto, propuesto por Benedict Anderson (1991: 6), de la nación como una comunidad imaginada.

6. La interesante y valiosa obra de Creedman, Historical dictionary of Costa Rica (1991), contiene una buena can-

tidad de artículos biográficos, pero combinados con otros sobre topónimos, instituciones, hechos históricos e información cultural variada. Por ello, mal podría ser considerado como un diccionario biográfico en sentido estricto. ces, el único diccionario generalnacional de Costa Rica que ha sido publicado. Esta sola circunstancia ya de por sí le haría acreedor de la debida atención, pero, además, es conveniente observarlo con detenimiento por cuanto constituye un resumen de las prácticas que deben evitarse a toda costa al elaborar un texto de este tipo.

El primer aspecto que resalta es el criterio de pertinencia empleado para seleccionar a los personajes merecedores de ser biografiados. Dicho criterio no se explicita, por lo que debe inferirse del propio texto. Así, por ejemplo, la generación de 1940, una de las más representativas de la literatura costarricense, brilla por su ausencia. Y no se trata de omisiones atribuibles a descuidos involuntarios, pues es dudoso el haber excluido a escritores de la relevancia de Carmen Lyra, Adolfo Herrera García, Fabián Dobles, Adela Ferreto, Joaquín Gutiérrez y Luisa González, y a otros pertenecientes a generaciones posteriores, como Alfredo Cardona Peña o Alfonso Chase. La conclusión cae por su propio peso: el criterio de selección es político (se obvia a los autores de orientación izquierdista), y esto se confirma si se considera el artículo correspondiente a 
Carlos Luis Fallas, uno de los dos únicos escritores comunistas7 que sí se reseñan:

Fallas, Carlos Luis.- Escritor. Trabajó varios años en las compañías bananeras como peón. Nació en 1912 y estuvo aprendiendo para zapatero, cursó apenas la escuela primaria, razón por la cual su modo de escribir es tan fresco y espontáneo. Fue diputado por el Partido Comunista y protagonista de la llamada revolución de 1948, como jefe de una de las fuerzas del Gobierno. Su obra más importante es "Mamita Yunai" y las colaboraciones publicadas en el órgano comunista Trabajo, cuando los comunistas eran financiados por Moscú y existía la Unión Soviética. Gran parte de su obra resulta ahora obsoleta, aunque es a veces un buen escritor. Se salvaron del derrumbe del Totalitarismo soviético, Marcos Ramírez, Gentes y gentecillas y Mi Madrina, cuyo principal atractivo es la sinceridad. Fallas murió en 1966. (Malavassi y Gutiérrez, 1992:84).

Las deficiencias de esta descripción son múltiples, pero solo se desta-

7. El otro es Carlos Luis Sáenz Elizondo, pero se le destaca únicamente como educador y se invisibiliza su faceta política (1992: 200). carán tres de las de mayor bulto. Primero, no respeta un orden cronológico como es normal en estos diccionarios: así, según Malavassi y Gutiérrez, Fallas primero es trabajador bananero, luego nace en 1912, es zapatero y va a la escuela, cuando la lógica y la historia dicen que, en estricta secuencia, Fallas nació en 1909, fue escolar, trabajador bananero y aprendiz de zapatero. Segundo, los comentarios sobre la producción literaria de Fallas son claramente políticos y cumplen una función deslegitimadora; además, se contradicen entre sí: ¿cómo es posible afirmar que la obra de Fallas resulta "obsoleta" y simultáneamente destacar que su novela más importante es Mamita Yunai y que "se salvaron del derrumbe del Totalitarismo soviético" Marcos Ramirez, Gentes y gentecillas y $M i$ Madrina, es decir, la práctica totalidad de sus textos literarios?8 Tercero, no emplea comillas para diferenciar los títulos de los libros del resto del texto, lo que ocasiona que, por el entorno de la descripción, Marcos Ramírez parezca más un disidente escapado del gulag soviético que el título de una novela.

Por el contrario, ante las omisiones injustificables de figuras mayores de la literatura costarricense, sí se inclu-

8. En realidad, solo excluye dos obras menores de Fallas: Tres cuentos (1968) y Un mes en la China roja (1957). 
yen las biografías de personas que no cumplen con el requerimiento de relevancia pública. Tal es el caso de las madres, hermanas, esposas e hijas de los presidentes de la República.

Ibarra, Antonia.- Dama nicaragüense madre del presidente Ascensión Esquivel, casada con el nicaragüense José María Esquivel. Esquivel gobernó del 8 de mayo de 1902 al 8 de mayo de 1906. El ex Presidente Esquivel se casó tres veces: la primera vez con Herminia Boza, de nacionalidad cubana; la segunda vez con Adela Salazar y la tercera con Cristina Salazar, hermana de la anterior (Malavassi y Gutiérrez, 1992:122).

Aquí, además de desaparecer el criterio de pertinencia, se diluye el principio mínimo de coherencia que debe regir la entera obra lexicográfica, puesto que el artículo termina por referirse ya no a Antonia Ibarra, sino a los devaneos conyugales de su ilustre hijo. Esto es, como lo insinuaba Saul, elevar el voyeurismo al rango de texto serio. 9

9. "La biografía ha reemplazado cada vez más la novela como la forma más popular de lectura seria. Mientras que en los siglos dieciocho y diecinueve la novela brindaba al lector un reflejo de sí mismo, hoy la biografía alienta los placeres gratuitos y el engaño del voyeurismo". (Saul, 2000: 42).
En relación con la presencia femenina en este diccionario, Yadira Calvo ha hecho unas críticas en verdad elocuentes: del total de 995 biografías, tan solo 135 son de mujeres (un $13,56 \%$ del total), y de ellas, 61 aparecen por su relación con hombres. Como señala Calvo, "la lección es clara: para las mujeres la boletería de la inmortalidad y la fama se abre a través del cuarto del niño y la cámara nupcial" (1997:12).

En el campo de los diccionarios biográficos de escritores, la situación no es mejor: se cuenta con tres trabajos. El primero de ellos, Quién es quién en la literatura costarricense, fue realizado en 1978 por un grupo de estudiantes de la Universidad de Costa Rica para uno de sus cursos, y se trata de una breve recopilación de datos sobre tan solo 30 escritores costarricenses vivos y que fue pensada como "una muestra de los principios de orden y estructura que se siguen para la elaboración de un 'Quién es quién" (Arce Delgado, 1978: 1). El segundo es el Diccionario biográfico literario de autores costarricenses 1940-1988 (1989) de Ana Cecilia Chávez Segura, el cual alcanza las 224 entradas. Se trata, sin duda alguna, de un gran y meritorio esfuerzo de compilación, que tiene en su favor la definición de una clara metodología que incluye tanto revisión bibliográfica como 
una encuesta dirigida a los escritores, y que se traduce en una planta que se respeta a lo largo del trabajo. Además de las limitaciones impuestas por las fronteras temporales elegidas, se puede indicar dos deficiencias fundamentales: al insertar comentarios sobre las características de la producción literaria emplea crítica no especializada, básicamente periodística, e incluso las opiniones de los escritores sobre sus propias obras. Esto produce reseñas impresionistas que poco o nada informan sobre las características textuales. En segundo lugar, se basa en fuentes secundarias y omitió verificar los datos mediante la consulta directa de los ejemplares de los textos literarios, lo cual determina la presencia de múltiples erratas, en especial en cuanto a los títulos de los libros. $1^{0} \mathrm{El}$ tercer intento es Biografías de literatos costarricenses

(1996) de Marco Tulio Mena Mena, que en realidad no es un libro, sino un manual de referencia para el uso de la Biblioteca Nacional. Reseña 107 escritores que publicaron después de 1970 e incluye algunos que solo han publicado

10. Por ejemplo, indica El libro de Ariadna (p. 647) en lugar de El hilo de Ariadna; Serenata longitud (p. 662) en vez de Serena longitud; y La estación que sigue el verano (p. 672) en vez de La estación que sigue al verano. en periódicos y revistas. Su mayor limitación proviene, nuevamente, del desconocimiento de teoría literaria y crítica especializada, con lo que sus comentarios son extraliterarios y muy imprecisos. $1^{1}$

En cuanto a los restantes diccionarios y catálogos biográficos especiales escritos en Costa Rica, predominan los referidos a figuras políticas (17), muy por encima de otras categorías: artistas (cuatro), científicos (tres), mujeres (dos), religiosos (uno) y educadores (uno).

\section{El Diccionario Biográfico de Escritores Costarricenses (DIBEC)}

Cuatro años atrás, luego de comprobar las limitaciones de los escasos diccionarios biográficos de escritores costarricenses, surgió el proyecto de reunir en un solo texto una gran cantidad de información que se encuentra dispersa o que, en muchos casos, en especial en lo referente a los escritores menos conocidos, simplemente no está disponible. Desde el 2005, el proyecto ha contado con el patrocinio del Instituto de

11. Por ejemplo, al referirse a la poesía de Luis Kleiman indica: "Se caracteriza por ser un hombre apasionado, que ama la vida, la belleza y que mantiene una posición clara de los valores morales, justicia y libertad". (Mena Mena, 1996: 148). 
Investigaciones Lingüísticas de la Universidad de Costa Rica, específicamente dentro del Programa de Estudios de Lexicografía HispanoCostarricense (ELEXHICÓS) que dirige el Dr. Víctor Manuel Sánchez Corrales. La idea fundamental que pretende marcar una diferencia respecto de los trabajos anteriores es la de combinar el rigor de las obras lexicográficas con los estudios críticos especializados más actuales sobre la literatura costarricense. El resultado de este trabajo debe ser un catálogo alfabético que recopile la mayor cantidad posible de escritores costarricenses. Cada artículo biográfico contendrá información vital básica (lugares y fechas de nacimiento y de muerte), profesión u oficio, estudios realizados, labores y cargos desempeñados, participación en grupos literarios, premios y distinciones recibidas, bibliografía activa detallada (editorial y año de las primeras ediciones de todos sus libros) y un comentario crítico sobre la producción literaria en general o sobre un texto en particular. El diccionario ofrecerá, además, un índice analítico de títulos de obras literarias y un desplegable que muestre una línea de tiempo, esto es, un cuadro sinóptico que relacione, según una distribución diacrónica y simultáneamente sincrónica, el quehacer literario costarricense con la tradición literaria latinoamericana y mundial y como parte del texto mayor de la cultura. El público meta es muy amplio y variado: desde escolares, estudiantes de secundaria y universidades, hasta especialistas en busca de una orientación mínima. En lo posible se evitará el tono ensayístico de muchos diccionarios de este tipo y se privilegiará en su sitio un estilo mucho más sintético. Se pretende producir, en suma, un texto de carácter didáctico, una obra de consulta ágil y moderna que combine el criterio enciclopédico con la seriedad lexicográfica.

Una interrogante básica que surge al plantearse este proyecto es: ¿debe ser exhaustivo o, por el contrario, selectivo? Alvar constata la imposibilidad de que el diccionario lingüístico contenga, como lo pretendía la definición del DRAE hasta su vigésima edición de 1984, todas las voces de una lengua (1980:105-106). Esta misma dificultad se enfrenta al elaborar un diccionario biográfico. Acometer la tarea de compilar la totalidad de los escritores de una literatura nacional representa una tarea enorme y más compleja de lo que puede suponerse. A despecho de la imagen extendida, casi convertida en lugar común, de que Costa Rica es un país de escaso desarrollo literario, se cuentan por centenas los escritores, algunos de ellos con una copio- 
sa bibliografía. Cada año, aparece una gran cantidad de nuevos textos, muchos provenientes de pequeñas editoriales o publicados en forma privada por sus autores, lo cual los hace de difícil localización; además, las leyes que obligan a la entrega de ejemplares a la Biblioteca Nacional y las bibliotecas universitarias se cumplen -cuando se cumplen- con desgano. De allí que un afán totalizador, exhaustivo, resulta muy difícil de satisfacer, por no decir imposible.

A pesar de estas dificultades, se ha optado por la exhaustividad como aspiración que oriente la entera labor investigativa, tanto porque significa un reto como porque uno de los grandes problemas de la investigación literaria en Costa Rica es su concentración en unos pocos autores y textos canónicos y su descuido de lo restante. Un diccionario exhaustivo ofrece la posibilidad de dar a conocer la existencia de múltiples textos que han sido invisibilizados por completo por parte de las instituciones literarias.

A partir de tal premisa, se han definido dos criterios de selección inclusivos o extensivos:

1) Nacionalidad: se incluirá a todos los escritores nacidos en Costa Rica y a aquellos nacidos en el extranjero, pero radicados temporal o definitivamente en Costa Rica y cuya obra se vincule de alguna forma con la cultura costarricense. Ejemplo de esto último es la inclusión de Máximo Soto Hall y Georges Vidal, y la exclusión de Rubén Darío.

2) Haber publicado textos literarios (novela, cuento, ensayo, poesía, drama) bajo el formato de libro. Se podrá hacer excepciones en los casos en que se considere que la producción del escritor ha tenido algún impacto en el mundo literario costarricense o, por cualquier motivo, revista alguna importancia. Por ejemplo, Domingo Jiménez, conquistador español, de quien se dice es el autor del primer texto literario escrito en Costa Rica.

Tras la definición de estos parámetros mínimos se procedió a establecer una planta que será utilizada en la redacción de los artículos y cuya importancia reside en dos aspectos: a) asegura el respeto de un esquema unificado de descripción; y b) permite determinar qué información es pertinente recabar para cada descripción. 


\section{Planta}

1) Nombre: negrita, letra 14. En caso de uso de seudónimo, se indica entre paréntesis.

2) Lugar y fecha de nacimiento y de muerte: entre paréntesis, letra 12.

3) Actividad.

4) Estudios efectuados (indicación de títulos obtenidos e institución educativa).

5) Trabajos y cargos públicos desempeñados.

6) Pertenencia a grupos o talleres literarios. Si se consigna el nombre de otro escritor también incluido en el DIBEC, se indicará la remisión con el uso de negrita.

7) Premios recibidos: énfasis en los premios nacionales (Aquileo Echeverría y Magón), Editorial Costa Rica, UNA-Palabra y Editorial de la Universidad de Costa Rica.

8) Textos literarios publicados bajo el formato de libro: título en cursiva y entre paréntesis indicación de la editorial y año de su primera edición. Se indicarán ediciones ulteriores solo en el caso de que representen una modificación significativa de la príncipe. Se tratará de agrupar los textos de acuerdo con criterios genéricos: novela, cuento, poesía, dramaturgia y ensayo.

9) Comentario sobre la producción literaria.

10) Textos publicados concernientes a otras áreas: título

en cursiva y entre paréntesis indicación de la editorial y año de su primera edición.

A continuación, se ofrece tres ejemplos de artículos del DIBEC realizados de conformidad con dicha planta. Para ello se ha seleccionado a escritores pertenecientes a diferentes grupos generacionales y que son significativos para nuestro campo de estudio. Se ha elegido a Ricardo Fernández Guardia por ser el pionero de los diccionarios biográficos en Costa Rica y a Arturo Agüero Chaves y Luis Ferrero Acosta por sus aportes a la lexicografía nacional. $1^{2}$

\section{Ejemplo 1}

Fernández Guardia, Ricardo (Alajuela, 1867 - San Isidro de Coronado, 1950). Historiador y diplomático. Realizó estudios primarios en Francia y, luego, en el Colegio de Alajuela y en el Instituto

12. Que este sea un modesto homenaje póstumo al maestro Ferrero, quien conoció y alentó este proyecto desde su inicio. 
Nacional, pero su formación fue básicamente autodidacta. Fue secretario de su padre, León Fernández, fundador de los Archivos Nacionales, y junto a él realizó investigaciones históricas en el Archivo de Indias en Sevilla, que culminarían con la publicación de la obra Historia de Costa Rica durante la dominación española (España, 1889). Desde 1885 desempeñó numerosos cargos diplomáticos, entre ellos el de embajador de Costa Rica en los Estados Unidos (1917). Ocupó el puesto de Director de los Archivos Nacionales (1930-1940) y a él se debe la fundación de la Revista de los Archivos Nacionales (1936). Fue declarado Benemérito de la Patria en 1950. Pertenece a la llamada Generación del Olimpo. A raíz de la publicación de su primer libro de relatos, Hojarasca (Tipografía Nacional, 1894), entró en polémica con Carlos Gagini sobre el nacionalismo en la literatura. En ella, Fernández Guardia, inspirado en las ideas del modernismo, defendió la libertad temática y lingüística del escritor; en tanto que Gagini sostuvo la noción de literatura como descripción de la realidad. Sus siguientes textos, Cuentos ticos (Imprenta María v. de
Lines, 1901) y la obra dramática Magdalena (Imprenta y Librería Española, 1902), significaron su acercamiento a la temática costarricense. Publicó, además, los relatos contenidos en La miniatura (Imprenta Alsina, 1920) y en Crónicas coloniales (Imprenta Trejos, 1921; segunda edición aumentada, Imprenta Trejos, 1937), estos últimos según el modelo inaugurado por las Tradiciones peruanas de Ricardo Palma. Entre 1931 y 1932 publica, en el periódico La Tribuna, una serie de crónicas tituladas Cosas y gentes de antaño que luego, con ese mismo título, recoge en forma de libro (Imprenta Trejos, 1935), segunda edición ampliada (Imprenta Trejos, 1939). Es autor de una extensa obra histórica, dentro de la que sobresalen Historia de Costa Rica: el descubrimiento y la conquista (1905), Cartilla Histórica de Costa Rica (1909), que constituyó durante décadas el texto por excelencia para la enseñanza escolar, Reseña Histórica de Talamanca (Imprenta Nacional, 1918), La Independencia y otros episodios (Editorial Borrasé, 1925), Morazán en Costa Rica (1941), Espigando en el pasado (Imprenta Atenea, 1946), y el primer diccionario biográfico 
del país: Diccionario biográfico de Costa Rica. Época de la conquista y la colonia (Sociedad de Geografía e Historia de Costa Rica, Publicación n. ${ }^{\circ} 1,1941$ ).

\section{Ejemplo 2}

Agüero Chaves, Arturo (San Isidro de Coronado, 1907-San José,). Educador y lingüista. Se graduó como maestro en la Escuela Normal en 1932 y luego como Profesor de Estado. Dirigió las escuelas de Ciudad Quesada, Naranjo y la República de Guatemala, fue profesor en el Liceo de Costa Rica y en la Universidad de Costa Rica, en donde impartió lecciones de Latín, Filología Románica, Gramática Comparada y otras disciplinas. Miembro de las Academias Costarricense, Hondureña yNorteamericana de la Lengua y Premio Nacional de Cultura Magón en 1984. Durante la década de 1930, colaboró con el periódico La Semana Cómica, dirigido por Pío Luis Acuña. $\mathrm{Su}$ Romancero Tico (Editorial Trejos Hermanos, 1940), segunda edición aumentada en 1953 (Editorial Aurora Social), de temática costumbrista y formas líricas tradicionales, se ubica dentro de la poesía postmodernista que, con un lenguaje claro y llano, busca representar el universo rural. Empleó los seudónimos de Sinforoso Retana, Cándido Sánchez y Pedro Díaz del Parral. Editó la Cifra antológica de Fabio Baudrit (EUCR, 1956). De su importante producción lingüística, enmarcada dentro de los postulados de la escuela filológica española, destacan las obras El Español de América y Costa Rica (Imprenta Lehmann, 1962), Origen y desarrollo de la lingüística (EUCR, 1977) y Diccionario de Costarriqueñismos (Asamblea Legislativa, 1996).

\section{Ejemplo 3}

Ferrero Acosta, Luis (Orotina, 1930 - San José, 2005). Ensayista y periodista cultural. Realizó estudios en el Colegio de México (1951-1955). Se inició en el periodismo en 1946 en Últimas Noticias, Mujer y Hogar y Mundo Femenino. Colaboró, además, en Diario de Costa Rica, La Prensa Libre, el suplemento cultural "Además..." de La República, en "Áncora" de $\mathrm{La}$ Nación (1975-1985), mantuvo la columna "Pensándolo bien" en el diario Al Día (1993-1995) y en numerosas revistas. Fue secretario personal y discípulo de Joaquín García Monge. Ocupó 
la jefatura del Departamento de Publicaciones del Ministerio de Educación Pública durante la década de 1950 y coordinó la cátedra de Literatura Infantil del Instituto de Formación Profesional del Magisterio. Realizó una amplia labor de apoyo a las bibliotecas de escuelas rurales (1969-1971) y como conferencista de temas arqueológicos. Ha sido miembro de la Junta Administrativa del Museo Nacional de Costa Rica (1977), asesor de Patrimonio Cultural del Ministerio de Cultura, Juventud y Deportes y curador del Museo de Arte Costarricense (1979-1981). Mereció el Premio Aquileo J. Echeverría en 1973 por La escultura en Costa Rica (ECR, 1973), en 1975 por Costa Rica precolombina (ECR, 1975), en 2002 por Mil y tantos tiquismos (EUNED, 2002) y el Premio Nacional de Cultura Magón en 1987. La obra de Ferrero, que alcanzó los 104 libros publicados, es una de las más vastas y diversas en el ámbito intelectual costarricense. Cultivó el ensayo en tres áreas principales: los estudios literarios, las artes plásticas y la arqueología y la historia indígenas. En el campo literario destacan la recopilación Literatura infantil costarricense (Ministerio de Educación Pública, 1950), Andrés Bello en Costa Rica (Ministerio de Educación Pública, 1962), La clara voz de Joaquín García Monge (Editorial Don Quijote, 1963), Manuel de Jesús Jiménez (Editorial Don Quijote, 1963), Brenes Mesén, prosista (Imprenta Trejos, 1964), La poesía folklórica costarricense (Imprenta Trejos, 1964), Ensayistas costarricenses (Imprenta Lehmann, 1971), Sociedad y arte en la Costa Rica del siglo 19 (EUNED, 1986), Perfiles al aire (Museo Histórico Cultural Juan Santamaría, 1986), Pensando en García Monge (ECR, 1989), Explosión creadora; tres ácratas costarricenses: Roberto Brenes Mesén, Joaquín García Monge y Omar Dengo (Universidad Nacional, 1995). Sus ensayos en el campo de las artes plásticas abarcan, entre otros: Amighetti grabador (Editorial Don Quijote, 1967), Carlomagno Venegas, esculturas (Ministerio de Educación Pública, 1971), Grabados en madera de Francisco Zúñiga (Imprenta Lehmann, 1973), Cinco artistas costarricenses; pintores y escultores (EUNED, 1985), Gozos del recuerdo. Ezequiel Jiménez y su época (Museo Histórico Cultural Juan Santamaría, 1987), Murales de César Valverde (Editorial L'Atelier, 1990), Edgar Zúniga, bronces (Editorial Varitec, 1990), Escultores costarricenses 1973-1990(ECR, 1992), 
Juan Ramón Bonilla, primer escultor costarricense del siglo 20 (Ediciones Mesén, 1999), José María Barrantes, arquitecto (ECR, 2003). En el área de la arqueología y temas indígenas puede señalarse Breve panorama prehistórico de Guanacaste (ANDE, 1974), Costa Rica precolombina (ECR, 1975), ¿Por qué prehistoria si hay historia precolombina? (EUNED, 1986), Entre el pasado y el futuro. Las culturas aborígenes de Costa Rica del Sector de Tradición Sudamericana a principios del siglo 16 (ECR, 1987), Los cacicazgos teocráticos en Mesoamérica (1500 a.C. - 200 d.C.) (MCJD, 1992) y Del oro precolombino costarricense (EUNED, 2002). Publicó, además, el libro de memorias Árbol de recuerdos (Editorial Don Quijote, 1968) y Pensándolo bien (EUNED, 2002), una recopilación de sus artículos en el periódico Al Día.

Los anteriores son ejemplos ideales de artículos, que no es posible igualar en todos los casos. Así, la información sobre algunos escritores es muy limitada o casi inexistente:

Gasparín (seudónimo). Autor de Un singular rapto aéreo (s.e., 1975), breve novela de aventuras que relata el secuestro de un avión por parte de extraterrestres.
Para el proceso de recopilación de materiales se estableció una secuencia de pautas que se ha venido ejecutando y que consiste en los siguientes pasos básicos:

a) Consulta de fuentes secundarias: manuales de historia y catálogos bibliográficos de la literatura costarricense, con el fin de levantar una lista preliminar de escritores costarricenses.

b) Consulta de bibliotecas. Revisión libro por libro de las secciones dedicadas a literatura costarricense en las bibliotecas universitarias. Los objetivos son varios: constatar la existencia física de cada libro (lo que minimiza el riesgo de cometer errores en títulos y fechas o dar por publicados textos que no pasaron del proyecto) y recabar información biográfica y editorial que se encuentra únicamente en los paratextos.

c) Visita a librerías y ventas de libros usados. Estas últimas son una fuente muy valiosa para el hallazgo de múltiples autoediciones de escasa circulación.

d) Establecimiento de contacto con grupos de escritores, tales como el Círculo de Escritores Costarricenses, el Círculo 
Literario de Guanacaste, Escritores y Editores de Pérez Zeledón, talleres literarios, etc.

e) Entrevistas a escritores.

f) Constitución de una red de colaboradores externos. Este es un recurso muy importante que permite la multiplicación de la capacidad investigativa y que no ha sido utilizado en el proceso de elaboración de los diccionarios biográficos costarricenses, pero que sí es frecuente en obras de gran complejidad y extensión. El caso paradigmático lo constituyen las 50000 biografías reunidas en los 60 volúmenes del Oxford Dictionary of National Biography (2004), $1^{3}$ resultado del esfuerzo combinado de 42 editores internos, 400 editores externos y, muy especialmente, casi 10000 colaboradores (profesores universitarios, investigadores independientes y escritores de muchas disciplinas) que participaron durante diez años, de 1992 al 2002, en su escritura.

Hasta el momento se ha cumplido con los pasos a), b) y c), y se ha obtenido una versión preliminar del DIBEC compuesta por alrededor

13. Se trata de una segunda edición, totalmente renovada en un 70 por ciento, del Dictionary of National Biography, publicado en 63 volúmenes entre 1884 y 1900. de 1016 entradas, cada una de las cuales representa una biografía. De este total, 758 entradas corresponden a hombres $(74,6$ por ciento) y 258 a mujeres ( 25,4 por ciento).

Los pasos d) y e) se pondrán en práctica a partir de marzo del 2006 y el paso f) fue sometido a prueba en el III Coloquio Costarricense de Lexicografía, celebrado en la Facultad de Letras de la Universidad de Costa Rica en noviembre del 2005, mediante la invitación a los participantes a convertirse en colaboradores externos del DIBEC.

Se estima que el trabajo final de redacción estará concluido, a más tardar, en diciembre del 2008.

\section{Bibliografía}

Ahumada, Lara I. 1989. Aspectos de lexicografía teórica, Granada, Servicio de Publicaciones de la Universidad de Granada.

Alvar, M. 2001. Colectánea lexicográfica, Madrid, Ediciones de Cultura Hispánica.

Alvar Ezquerra, M. 1976 Proyecto de Lexicografía Española, Madrid, Editorial Planeta.

Alvar Ezquerra, M. 1980. “¿Qué es un diccionario? Al hilo de unas definiciones académicas", en Lingüística Española Actual, II (1), pp. 103-118.

Anderson, B. 1991. Imagined communities, Londres, Verso. 
Calvo, Y. 1997. Presentación, en Zeledón Cartín E. Surcos de lucha. Libro biográfico, histórico y gráfico de la mujer costarricense, San José, Universidad Nacional.

Haensch, G. 1982. “Tipología de las obras lexicográficas», en Haensch et alii La Lexicografía. De la lingüistica teórica a la lexicografía práctica, Madrid, Editorial Gredos, pp. 95 - 187.

Hernández, H. 1994. “Diccionarios enciclopédicos", en Hernández H. (coord.) Aspectos de Lexicografía Contemporánea, Barcelona, Bibliograf S.A., pp. 61-69.

Martínez de Sousa, J. 1995. Diccionario de lexicografía práctica, Barcelona, Bibliograf S.A.

Mederos, H. 1994. "A propósito de la definición lexicográfica, en Hernández H. (coord..) Aspectos de Lexicografía Contemporánea, Barcelona, Bibliograf S.A., pp. 95 - 106.

Pozuelo Yvancos, J. M. 1992. Teoría del Lenguaje Literario, Madrid, Cátedra.

Saul, J. R. 2000. Diccionario del que duda, Barcelona, Ediciones Granica S.A.

Seco, M. 1987. Estudios de lexicografía española, Madrid, Paraninfo S.A.

Slocum, R. 1967. Biographical dictionaries and related works, Detroit, Gale Research Company.

Víquez, A. 2002. Biografías de hombres ilustres, San José, EUNED.

\section{Diccionarios biográficos}

\section{costarricenses y textos afines}

Academia de Historia y Geografía de Costa Rica 1978. Gobernantes de Costa Rica, San José, Editorial Texto.

Albertazzi Avendaño, R. 1985. Quién es quién en política, San José, Publicidad Roala S.A.

Arce Delgado, J.R. et al. 1978. ¿Quién es quién en la literatura costarricense?,
Trabajo para el curso Referencia II, Facultad de Educación, Universidad de Costa Rica.

Banco Central de Costa Rica. 1970. XX Aniversario Exposición de Pintura Costarricense, San José, Banco Central de Costa Rica.

Biblioteca Nacional 2003. Repertorio biográfico de científicas y científicos costarricenses, San José, Biblioteca Nacional.

Blanco Segura, R. 1984. Obispos, Arzobispos y Representantes de la Santa Sede en Costa Rica, San José, EUNED.

Bonilla, H. 1979. Los Presidentes, San José, EUNED-Editorial Costa Rica, 2 vol.

Chávez, Segura A.C. 1989. Diccionario biográfico literario de autores costarricenses (1940-1988), Tesis de Licenciatura en Bibliotecología, Universidad de Costa Rica.

CONICIT. 2000. Datos biográficos de cientificos / especialistas costarricenses, San José, CONICIT.

Creedman, T. 1991. Historical dictionary of Costa Rica, Metuchen, New Jersey, Scarecrow.

Donoso Michelena, B. 1990. El Libro del Recuerdo, San José, Editorial El Libro del Recuerdo S.A., 4 vol.

Durán Muñoz, L. 1997. Premio Nacional de Ciencia y Tecnología Clodomiro Picado Twight XX Aniversario 1976-1996, San José, EUNED, Ministerio de Ciencia y Tecnología.

Fernández Guardia, R. 1941. Diccionario biográfico de Costa Rica. Epoca del Descubrimiento y la Conquista, en Sociedad de Geografia e Historia de Costa Rica, Publicación n.o 1, pp. 3-45.

Fernández Mora, C. 1956. Semblanzas: algunos valores de Costa Rica, San José, Imprenta Vargas. 
Fernández Rivera, F. 1984. Presidentes de congresos, asambleas y convenciones constituyentes 1824 a 1949, San José, Asamblea Legislativa.

Fernández Rivera, F. 1985. Presidentes de las Cámaras de diputados y representantes, San José, Asamblea Legislativa.

Fernández Rivera,F. 1986. Beneméritos de la patria, San José, Asamblea Legislativa.

Fernández Robles,J.A. 1979. Presidentes ejecutivos, gerentes, subgerentes, miembros de la junta directiva, auditores y subauditores de la Caja Costarricense de Seguro Social, San José, Caja Costarricense de Seguro Social.

Fernández Robles,J.A. 1980. Funcionarios a nivel de gobierno y administración superior del Instituto Nacional de Aprendizaje 19651980, San José, INA.

Freer O'Connor, R. 1981. Políticos de Costa Rica: biografias de los más importantes hombres en quienes descansa el futuro de Costa Rica, San José, Fremy \& Cassel.

González Víquez, C. 1936. "Personal del Poder Ejecutivo en Costa Rica", en Revista de los Archivos Nacionales, n.․ 1-2.

Madrigal Soto, V. et al. 1978. Quién es quién en el arte costarricense, Trabajo para el curso Referencia II, Facultad de Educación, Universidad de Costa Rica.

Malavassi, G. y Gutiérrez P.R. 1992. Diccionario biográfico costarricense, San José, Universidad Autónoma de Centroamérica.

Mena Mena, M.T. 1996. Biografias de literatos costarricenses, San José, Ministerio de Cultura, Juventud y Deportes.

Obregón, C. 1999. Nuestros gobernantes. Verdades del pasado para comprender el futuro, San José, Editorial de la Universidad de Costa Rica.

Obregón, Loría R. 1948. Nuestros gobernantes, San José, Editorial Aurora Social.
Obregón, Loría R. 1979. De nuestra historia patria. Los gobernadores de la colonia, San José, Universidad de Costa Rica.

Oconitrillo, E. 2000. Los grandes perdedores: semblanza de dieciocho políticos costarricenses, San José, Editorial Costa Rica.

Sáenz Carbonell, J.F. 1994. Los Ministros de Gobernación, San José, Imprenta Nacional.

Sáenz Carbonell, J.F. et al. 2001. Las primeras damas de Costa Rica, San José, ICE.

Sáenz Carbonell, J.F. et al. 1986 Los cancilleres de Costa Rica, San José, Imprenta Nacional.

Solera Rodríguez, G. 1963. Costarricenses ilustres. Servidores de la enseñanza, San José, Librería e Imprenta Atenea.

Solera Rodríguez, G. 1967. Expresidentes de la Corte Suprema de Justicia 1825-1955, San José.

Solera Rodríguez, G. 1968. Antología. Escritores y artistas heredianos, San José, Imprenta Nacional.

Varios. 1940. Los Conquistadores, San José, Imprenta Lehmann.

Who's who in Costa Rica 1979-1980: professions, commerce, government, San José, A.E. Huper.

Zeledón Cartín, E. 1985. Anteproyecto Diccionario Biográfico Costarricense, mimeografiado.

Zeledón Cartín, E. 1988. Los Magones, San José, Ministerio de Cultura, Juventud y Deportes.

Zeledón Cartín, E. 1997. Surcos de lucha. Libro biográfico, histórico y gráfico de la mujer costarricense, San José, Universidad Nacional.

Zeledón Cartín, E. 1992. Los Premio Magón, San José, Editorial Costa Rica. 